\title{
Combination of mechanical and chemical pre-treatments to improve nitriding efficiency on pure iron.
}

\author{
V. Lacaille ${ }^{\mathrm{a}}$, V. Peres ${ }^{\mathrm{e}}$, C. Langlade ${ }^{\mathrm{b}}$, C. Morel $^{\mathrm{c}}$, E. Feulvarch $^{\mathrm{d}}$, J.-M. \\ Bergheau $^{\mathrm{d}}$, G. Kermouche ${ }^{\mathrm{e}}$ \\ ${ }^{a}$ EIGSI, La Rochelle, France \\ ${ }^{b}$ UBFC, IRTES-LERMPS, 90010 Belfort, France \\ ${ }^{c}$ Winoa, 528 avenue de Savoie, BP3, 38570 Le Cheylas, France \\ ${ }^{d}$ Univ. Lyon, ENISE, LTDS, UMR 5513 CNRS, 58 rue Jean Parot, 42023 Saint-Etienne \\ Cedex 2, France \\ ${ }^{e}$ École des Mines de Saint-Etienne, LGF UMR 5307 CNRS, 158 Cours Fauriel 42023 \\ Saint-Etienne, France
}

\begin{abstract}
In this paper, the efficiency of gas nitriding on pure iron is observed regarding two types of pre-treatments prior to nitriding: chemical reduction by $\mathrm{H}_{2}$ and nanocrystallization by NanoPeening ${ }^{\circledR}$. Thermogravimetric analysis reveals that both pre-treatments result in an increase in the transformation rate of nitrogen during the first $200 \mathrm{~min}$ of nitriding. Moreover, glow discharge optical spectrometry reveals that nanocrystallization by NanoPeening ${ }^{\circledR}$ leads to a deeper penetration of nitrogen in the material.

Keywords: Thermogravimetric analysis; nitriding; pure iron; nanocrystalline material; oxide reduction.
\end{abstract}

\section{Introduction}

Manufacturing surface having high near-surface mechanical properties (hardness, compressive residual stresses) is one of the major challenges for increasing the lifetime of mechanical parts. Surface mechanical treatments like shot peening, or thermochemical techniques like nitriding, lead to compressive residual stresses [1] which prevent the initiation of cracks. To face abrasive and adhesive wear, it is well known that hardness has to be maximized. One way 
to obtain higher near-surface mechanical properties without changing materials composition is to use surface mechanical treatments, which can induce grain fragmentation resulting in ultrafine grains or nano-sized grains $[2,3,4]$. This leads naturally to an increase in hardness and yield stress thanks to the wellknown Hall-Petch effects [5, 6] as shown by Tumbajoy-Spinel et al [7].

Such nanocrystallization treatments offer one other significant advantage: the enhancement of diffusion phenomena thanks to the increase in grain boundaries density. As shown by Tong et al., the Surface Mechanical Attrition Treatment (SMAT) leads to deep penetration of nitrogen upon nitriding at $300^{\circ} \mathrm{C}$ of an austenitic stainless steel. Let us highlight the fact that nitriding of such materials at such a temperature is usually inefficient on non-mechanically treated samples. Gu et al. [8] observed on a low carbon steel, that SMAT prior to nitriding improves the thickness of the nitrided layer. Moszynski et al. [9] studied the nature of nitride phases formed during nitriding on nanocrystalline iron and showed that nanocrystallization induces the stability of ironnitrogen phases that cannnot be observed with coarse grain material. They also showed that the compound layer formation requires a lower nitriding potential than in the case of coarse grain material [10]. The penetration depth of nitrogen was observed to be double compared to nitriding used alone. Lin et al. [11], Tong et al. [12] and Prezeau et al. [13], also showed on different steel grades (respectively AISI 321, 38CrMoAl, AISI 304L, 32CrMoV13 and X37CrMoV5-1) that surface nanocrystallization prior to nitriding increases the hardness after treatment. Terres et al. [14] showed on $42 \mathrm{CrMo} 4$ steel that the compressive residual stresses obtained by shot peening can be combined to those obtained by nitriding, leading to an improvement of the fatigue resistance.

Nevertheless it is apparent, that the benefits of associating these two treatments are sometimes a matter of debate. For instance, the increase in fatigue resistance is not observed by Hassani et al. [15] who investigated the combination of nanostructuration by severe shot peening and nitriding on $32 \mathrm{Cr}$ MoV13 steel. However, they highlighted that for equivalent output proper- 
ties (hardness, fatigue limit and residual stresses), the nitriding duration on a $35 \mathrm{NiCrMoV} 12-5$ steel can be reduced by applying a nanocrystallization pretreatment [16]. Manfridini et al. [17] also observed on Ti-stabilized interstitialfree steels that the combination of such treatments does not improve mechanical properties compared to single treatments, but no information about the gain in nitriding duration is given. Chemki et al. [18] showed on austenitic steels that the nitriding efficiency could be further improved if SMAT was followed by a slight polishing step, pointing out that nanocrystallized layers can sometimes be accompanied by side effects (e.g. surface oxidation) that play a detrimental role on diffusion.

In practical conditions, oxide layers can act as a barrier to the diffusion of nitrogen. Thus, it is well known that a chemical cleaning by reduction of oxides improves the efficiency of nitriding $[19,20]$. For example, De Las Heras et al. [21] prepared their samples by heating them in a 50/50 $\mathrm{Ar} / \mathrm{H}_{2}$ mixture for $3 h$ before nitriding. Jones [22] observed an increase in the hardness on AISI 4140 steel after nitriding when samples where initially pre-oxidized and reduced during nitriding.

Most of investigations about the combination of nitriding with mechanical pretreatments are based on post-mortem mechanical and microstructural characterization. Only a few of them address the consequences of such pretreatments on nitriding kinetics. This is the aim of the present paper. For that purpose an extensive analysis of the nitriding kinetics is performed using thermogravimetric analysis and Glow Discharge Optical Emission Spectroscopy to obtain an in-depth nitrogen profile after nitriding. These investigations are conducted on pure iron samples, chosen as model material, which are successively submitted to two types of surface pre-treatments before nitriding:

- Surface nanocrystallization by NanoPeening ${ }^{\circledR}[4]$;

- Chemical surface preparation by reduction.

The effects of each pre-treatment and their combination on the nitriding kinetics are carefully examined, which has never been done to the knowledge of the 


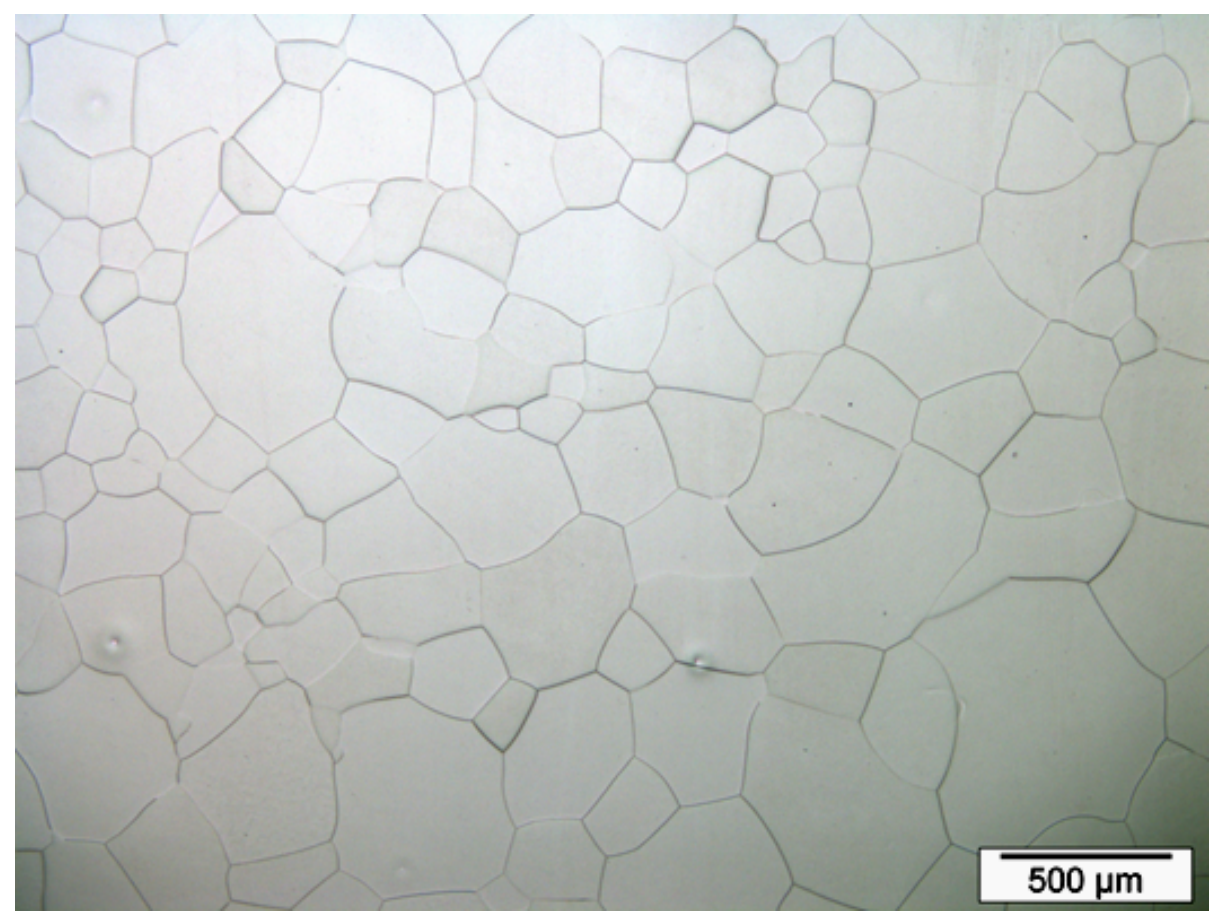

Figure 1: Optical micrography of the pure iron used

authors.

\section{Materials and methods}

\subsection{Material}

The samples used for this study are pure iron cylinders of $\Phi 11 \mathrm{~mm}$ diameter obtained by cold crucible melting, which leads to a level of impurities lower than $15 \mathrm{ppm}$. Figure 1 shows an optical micrography of the corresponding microstructure. The average grain size is estimated to be $280 \mu \mathrm{m}$.

\subsection{Nanocrystallization treatment}

The cylinders are cut into $5 \mathrm{~mm}$ thick pins as presented in figure 2a. Both sides of these pins receive a NanoPeening ${ }^{\circledR}$ treatment. This treatment is a mechanical treatment developed by Winoa group [4] and consists of blasting steel balls ( 0.1 to $2 \mathrm{~mm}$ diameter) on the sample surface. Nanocrystallization by 


\begin{tabular}{l|ccc}
\hline \hline Nomenclature & NN & NPS & NPL \\
NanoPeening ${ }^{\circledR}$ surface coverage & $0 \%$ & $100 \%$ & $5000 \%$ \\
Polishing method & Mechanical & None & None \\
Polishing duration & $60 \mathrm{~s}$ & 0 & 0 \\
Polishing granulometry & ISO P600 & None & None \\
Abrasive paper material & SiC & None & None \\
\hline \hline
\end{tabular}

Table 1: NanoPeening ${ }^{\circledR}$ treatment parameters

severe plastic deformation of the near surface is obtained by projecting the balls with an impact angle between $10^{\circ}$ and $45^{\circ}$ at a speed between 40 and $100 \mathrm{~m} . \mathrm{s}^{-1}$. The treatment can be of many types. 3 are considered in this study, as shown on figure $2 \mathrm{~b}$. Table 1 sums up the NanoPeening ${ }^{\circledR}$ treatment parameters. The only difference between NPS and NPL treatment types lies in their surface coverage, directly proportional to the treatment duration; the NPL treatment lasts 50 times longer than the NPS treatment. In order to analyze the effects of the mechanical treatment, the reaction of the circumferential surface of the pins has to be negligible compared to the reaction happening on the treated surface. For that purpose, the pins are cut under water into $1 \mathrm{~mm}$ thick plates, as shown on figure 2c. The surface obtained due to the cutting operation is polished with the same conditions as NN treatment. Then, the prepared samples present a side having received an NN treatment, and another side having received either an NN, an NPS or an NPL treatment.

The nanostructured layer obtained on NPL samples is described in an other study by Lacaille et al. [23] and Tumbajoy et al. [7]. EBSD measurements are coupled to a grain size model as a function of the depth proposed by Tao et al. [3]. Figure 3b presents the grain size measurements as a function of the depth. The model from Tao et al. is the grain size fit. Hardness measurements carried out by Tumbajoy et al. [7] as a function of the depth show that the hardness improvement due to nanostructuration is located in the first microns. It permits evaluation of the thickness of the nanostructured layer and the minimum grain size as mentioned in table 2 . 


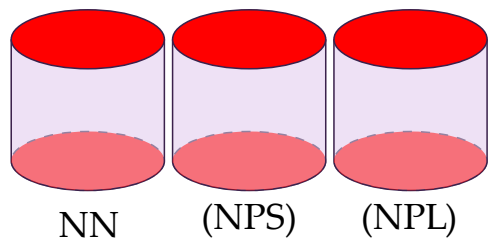

(a) After Cutting

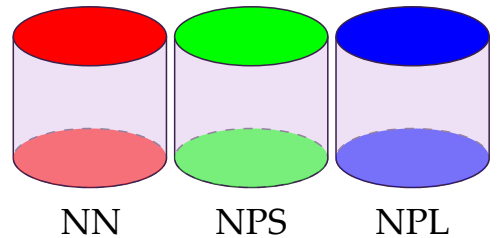

(b) After surface mechanical treatment

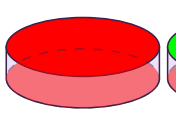

NN

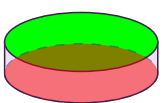

NPS

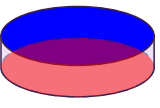

NPL

(c) After second cutting

Figure 2: Samples mechanical preparation

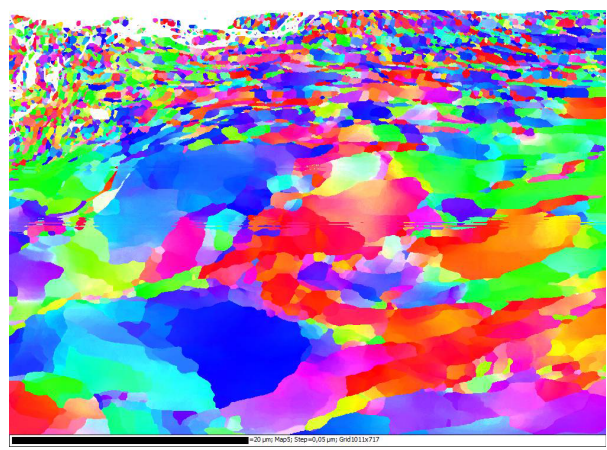

(a) EBSD view

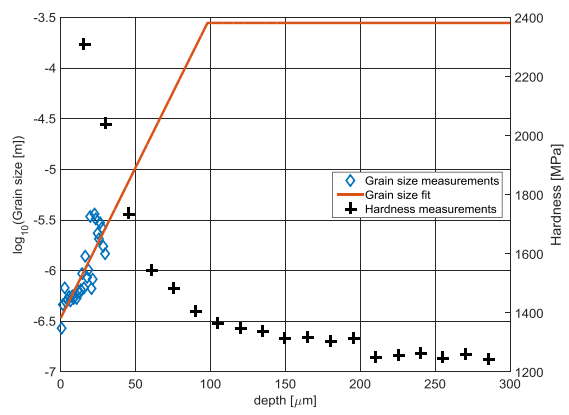

(b) Grain size and hardness measurements

Figure 3: EBSD view and grains size and hardness measurements, according to Tumbajoy et al., Lacaille et al. and Tao et al. [7, 23, 3]

\begin{tabular}{l|c}
\hline \hline Thickness of the nanostructured layer & $60 \mu \mathrm{m}$ \\
\hline Minimum grain size & $502 \mathrm{~nm}$ \\
\hline \hline
\end{tabular}

Table 2: Parameters of the nanostructured layer on NPL samples following [23] and [7] 


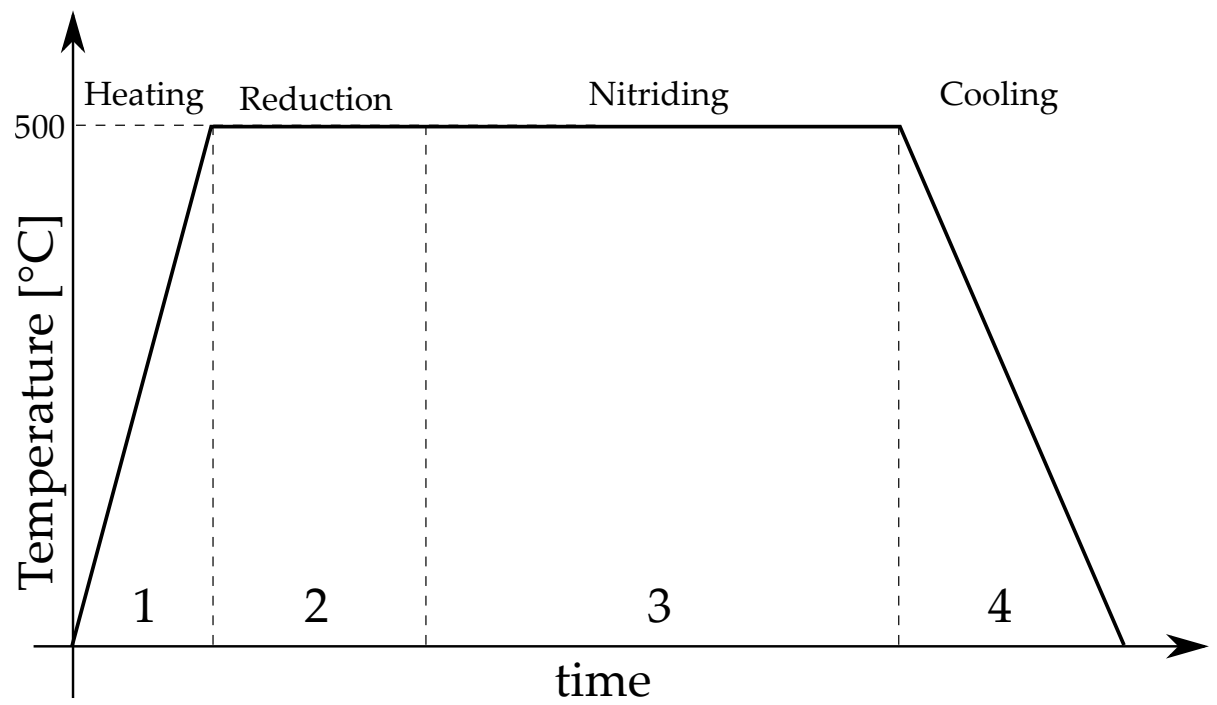

Figure 4: Description of the thermochemical cycle

\subsection{Thermochemical Treatment}

The nitriding and reduction kinetics is studied using a symmetric thermobalance device (SETARAM TAG-24). The thermochemical cycle is composed of 4 steps as presented in figure 4:

1. The increase in the temperature up to $500{ }^{\circ} \mathrm{C}$ at $30{ }^{\circ} \mathrm{C} / \mathrm{min}$ under $\mathrm{He}$.

2. An isothermal reduction step under a mixture of $\mathrm{He}(3.875 \mathrm{~L} / \mathrm{h})$ and $H_{2}(0.125 \mathrm{~L} / \mathrm{h})$ with different durations (from 10 to 360 minutes).

3. An isothermal nitriding step under a mixture of $\mathrm{He}(2 L / h), \mathrm{N}_{2}$ $(1.4 \mathrm{~L} / \mathrm{h})$ and $\mathrm{NH}_{3}(0.6 \mathrm{~L} / \mathrm{h})$ with different durations (from 60 to 360 minutes).

4. The cooling rate of $30^{\circ} \mathrm{C} / \mathrm{min}$ under $\mathrm{He}(3 \mathrm{~L} / \mathrm{h})$.

The reduction and nitriding conditions, especially the content of dihydrogen and ammonia in the gas mixtures, were chosen to respect safety limits. 


\subsubsection{Oxides reduction}

Oxides reduction by $H_{2}$ under $570{ }^{\circ} \mathrm{C}$ can be described as following, according to Wagner [24]:

$$
\left\{\begin{array}{l}
3 \mathrm{Fe}_{2} \mathrm{O}_{3}+\mathrm{H}_{2}=2 \mathrm{Fe}_{3} \mathrm{O}_{4}+\mathrm{H}_{2} \mathrm{O} \\
\mathrm{Fe}_{3} \mathrm{O}_{4}+4 \mathrm{H}_{2}=3 \mathrm{Fe}+4 \mathrm{H}_{2} \mathrm{O}
\end{array}\right.
$$

\subsubsection{Nitriding}

As mentioned by Somers et al. [25], iron nitriding by $\mathrm{NH}_{3}$ can be described by two processes:

1. Dissociation of $\mathrm{NH}_{3}$ into adsorbed nitrogen $N_{(a d)}$ and adsorbed hydrogen $H_{(a d)}$.

2. Recombination of $H_{(a d)}$ into $H_{2}$ and $N_{(a d)}$ into $N_{2}$ and dissolved nitrogen $[N]$, depending on the ammonia partial pressure and on the temperature.

\subsection{Nomenclature}

In this paper, 16 samples are prepared and analyzed. The following nomenclature is proposed to identify a sample:

$$
x-R y-N z
$$

Where $x$ corresponds to the mechanical treatment type (NN, NPS or NPL) and $y$ and $z$ are respectively the reduction and nitriding durations expressed in minutes. Table 3 presents the whole set of samples studied in the present paper, with the analyses they were submitted to. It will be noticed that there is no case where the sample received stricly only the nanostructuration before nitriding. As a result, it should not be possible to investigate the effect of this pre-treatment alone on nitriding. However, when the reduction time is as short as $10 \mathrm{~min}$, it seems reasonable to consider that the samples were "NN only", "NPL only" or "NPS only". Besides, standard nitriding treatments usually start with a reduction step ${ }^{1}$ even though it is not always mentioned.

\footnotetext{
${ }^{1}$ It is often referred to as "cleaning under $\mathrm{H}_{2}$ ".
} 


\begin{tabular}{lcc}
\hline \hline Sample & TG & GDOES \\
\hline NN-R10-N120 & Yes & Yes \\
NN-R10-N240 & Yes & Yes \\
NN-R10-N360 & Yes & Yes \\
NN-R360-N60 & Yes & No \\
\hline NPS-R14-N360 & Yes & No \\
NPS-R240-N210 & Yes & Yes \\
NPS-R300-N120 & Yes & Yes \\
\hline NPL-R10-N360(1) & Yes & Yes \\
NPL-R10-N360(2) & Yes & No \\
NPL-R10-N240 & Yes & No \\
NPL-R210-N120 & Yes & Yes \\
NPL-R300-N120 & Yes & Yes \\
NPL-R360-N60 & Yes & No \\
\hline \hline
\end{tabular}

Table 3: List of all analyses conducted (TG: Thermogravimetric - GDOES: Glow Discharge Optical Emission Spectrometry)

This is why the conditions with $R 10$ can be considered representative of the isolated effect of nanostructuration.

\section{Results}

\subsection{Thermogravimetric analysis}

In this section, the analysis is led during the first hour of nitriding and all the samples have been nitrided for a minimum suration of $1 h$. The usual way to present the results in thermogravimetric analysis is to divide the mass by the reaction area. In this study, each side has received a different surface mechanical treatment, so it is not suitable to do such an operation. Thermogravimetric measurements are then presented with the total mass, corresponding to the reaction of both nanostructured and non-nanostructured faces. The comparison between samples still remains possible given that all of them have the same dimensions.

\subsubsection{Not nanostructured samples (NN)}

Figure 5 presents the thermogravimetric curves for not nanostructured samples. A mass loss occurs during nitriding, around $500 s$ and its intensity decreases with the reduction duration. There is a peak in the transformation 


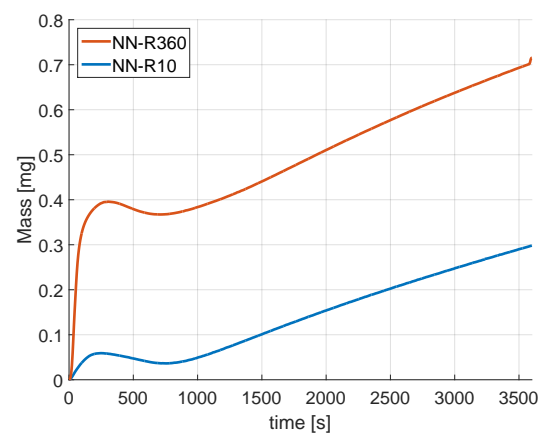

(a) Mass

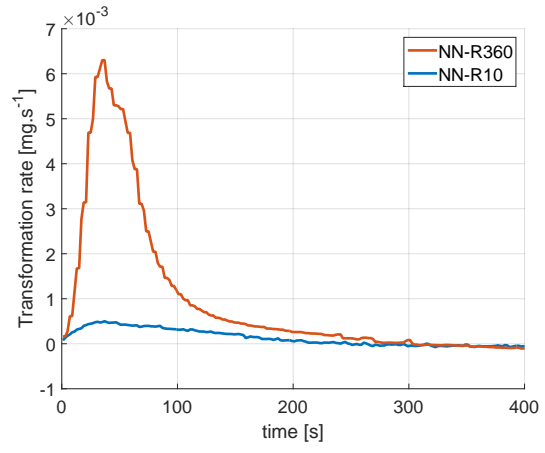

(b) Tranformation rate

Figure 5: Thermogravimetric measurements for two NN samples reduced for 10 and $360 \mathrm{~min}$. The transformation rate measurements focuses on the first minutes of nitriding. In order to simplify the reading, the nitriding duration is not given in the nomenclature. The time $0 s$ corresponds to the beginning of the nitriding step.

rate within the first $100 s$ for the sample reduced for the longest duration (6h). It leads to a higher mass after $1 h$. The maximal value of the transformation rate for the sample reduced for a period of $6 h$ is approximately 12 times the one of the sample reduced for $10 \mathrm{~min}$. After $300 \mathrm{~s}$, the transformation rate is equivalent for both samples.

\subsubsection{Nanostructured samples (NPS and NPL)}

Figures 6 and 7 present the thermogravimetric curves for nanostructured samples. They respectively correspond to NPS samples and NPL samples. As mentioned for not nanostructured samples, there still remains a mass loss during nitriding with a lower intensity than NN samples. All nanostructured samples present a peak in the transformation rate during the first $3-4$ min. The maximal value of this peak increases with the reduction duration and the nanostructuration duration. It also leads to an increase in the final mass.

\subsubsection{Reproducibility of the thermogravimetric analysis}

One can see on figure $7 \mathrm{~b}$ three NPL samples that have been reduced for the same duration, $10 \mathrm{~min}$. For those samples, the transformation rate curves are very close to each other, which indicates a low dispersion of the thermogravi- 


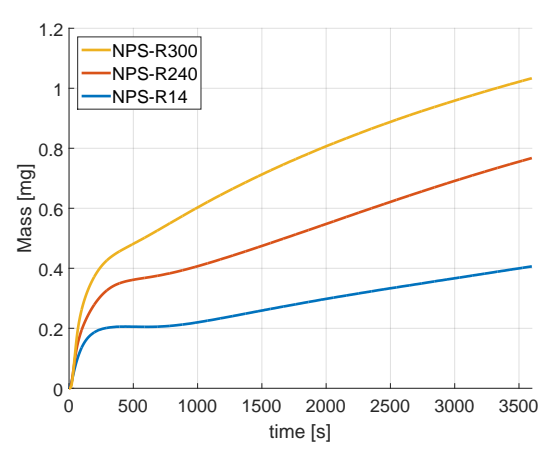

(a) Mass

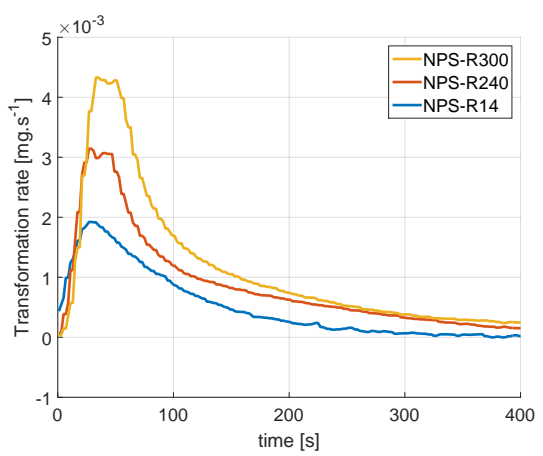

(b) Transformation rate

Figure 6: Thermogravimetric measurements for NPS samples. The transformation rate measurements focus on the first minutes of nitriding. In order to simplify the reading, the nitriding duration is not given in the nomenclature.

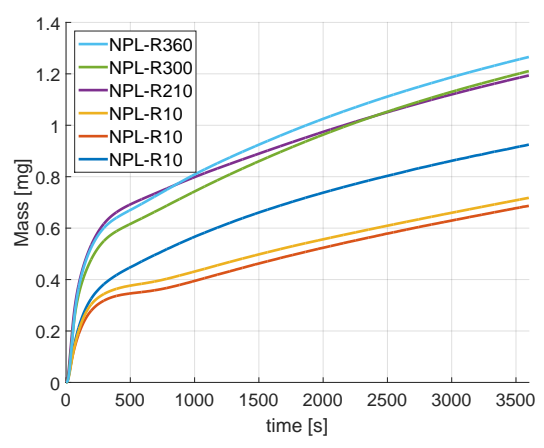

(a) Mass

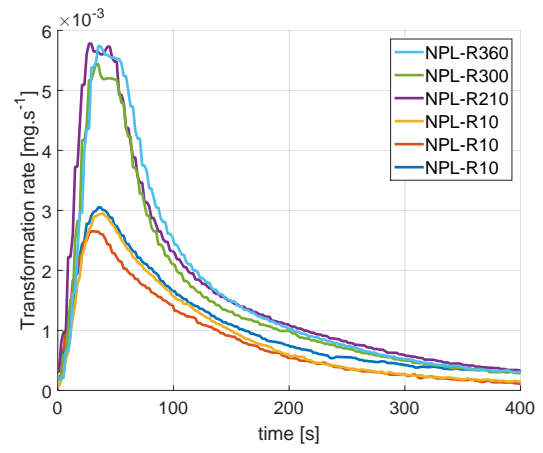

(b) Transformation rate

Figure 7: Thermogravimetric measurements for NPL samples. The transformation rate measurements focus on the first minutes of nitriding. In order to simplify the reading, the nitriding duration is not given in the nomenclature. 


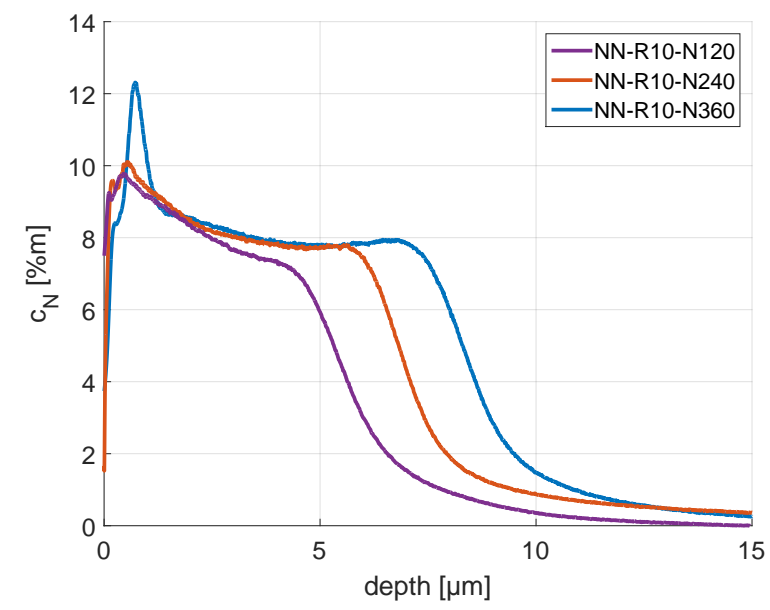

Figure 8: Nitrogen depth profiles for NN samples reduced for $10 \mathrm{~min}$

metric analysis during the first minutes. For two of the three samples, there is a mass loss around $400-600 \mathrm{~s}$. It leads to different masses after nitriding.

\subsection{Elemental depth profiles analysis}

All the samples have different reduction, nanostructuration and nitriding conditions. An extensive systematic study of nitrogen concentration profiles in regards to pre-treatments conditions would be required to highlight the respective influences of nanostructuration and reduction. In this paper, the set of GDOES measurements has not been designed in that way. However, some comparisons can still be made.

\subsubsection{Not nanostructured samples (NN)}

Figure 8 presents the nitrogen concentration profiles of not-nanostructured samples which have been reduced for a period of $10 \mathrm{~min}$ and nitrided for $2 h$ to $6 h$. As expected, the nitrogen penetrates deeper in the material when the nitriding duration increases. The concentration profiles present a plateau, as predicted by Torchane et al. [26]. 


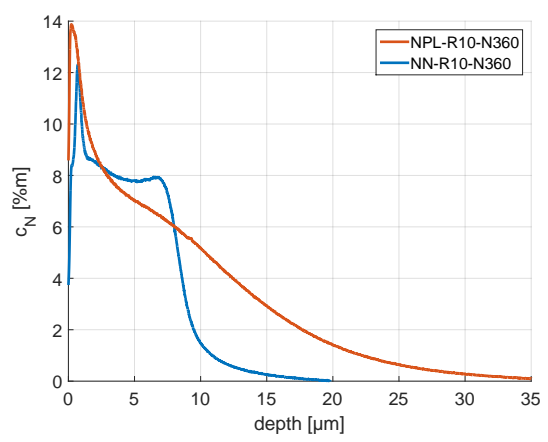

(a) $10 \mathrm{~min}$ reduction and $6 \mathrm{~h}$ nitriding

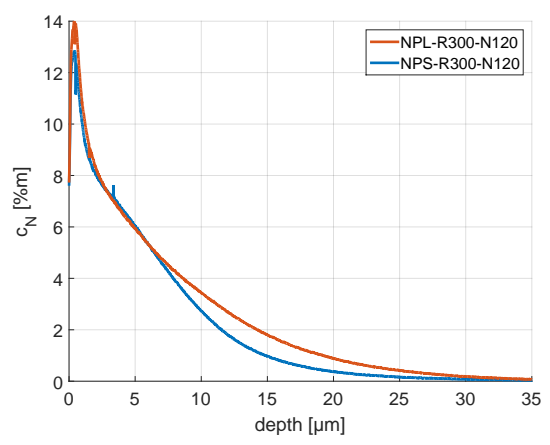

(b) $5 h$ reduction and $2 h$ nitriding

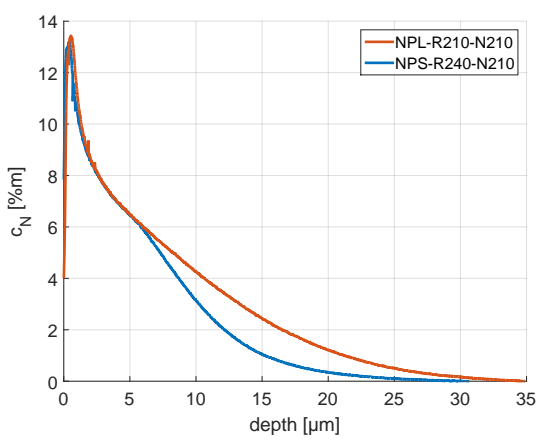

(c) $3 h: 30 \mathrm{~min}-4 h$ reduction and $3 h: 30 \mathrm{~min}$ nitriding

Figure 9: Comparison of the nitrogen depth profiles for several samples. Influence of the nanostructuration duration

\subsubsection{Nanostructured samples}

As mentioned above, the available samples do not enable investigation of the influence of the reduction duration. Nevertheless, it is still possible to extract the influence of nanostructuration. Figure 9 shows its influence for different reduction times.

Figure 9a shows a particular measurement which has been led on both sides of the same sample. According to the section 2.2 they correspond to a NN face and an NPL face. It shows that the concentration plateau disappears with nanostructuration but the nitrogen penetrates deeper in the material.

Figure $9 \mathrm{~b}$ shows that for a high reduction duration, nitrogen penetration 
depth is slightly higher in the samples submitted to a NPL treatment compared to those submitted to an NPS treatment.

Figure $9 \mathrm{c}$ shows that for a low reduction duration, the same effect can be observed.

\section{Discussion}

Thermogravimetric analysis shows that there is a mass loss during nitriding for low reduction durations. This mass loss might be a consequence of the presence of iron oxides which have not been completely reduced before nitriding. As a matter of fact, dissociation of $\mathrm{NH}_{3}$ leads to the formation of $\mathrm{H}_{2}$ as explained in section 2.3.2. The released $H_{2}$ becomes the actor of a reduction reaction which occurs during nitriding on the remaining iron oxides. As Jones [22] observed an improvement of hardness after nitriding on samples which were previously

oxidized, this improvement might be a consequence of oxides reduction during nitriding.

Regarding the transformation rate, a pre-reduction treatment before nitriding leads to an acceleration of nitrogen penetration during the first minutes. It results in a peak in the rate of mass curves, with an intensity increasing with the reduction duration. Two main hypotheses can explain this phenomenon, firstly based on the fact that reduction leaves voids where the oxides were initially present :

- The reaction surface area without oxides is higher than with non-reduced oxides.

- When reduced, the surface of the sample presents native Fe. Its ability to trap nitrogen is then higher than with oxides. Similar conclusions have been brought by Bonnet to explain carbon diffusion enhancement after iron oxides reduction [27].

From a purely chemical point of view, a third hypothesis can explain this phenomenon : 


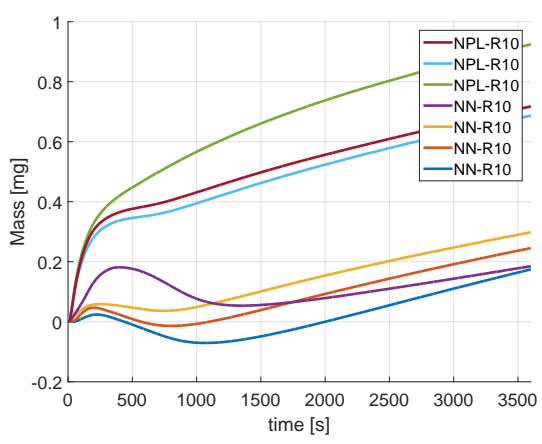

(a) Mass

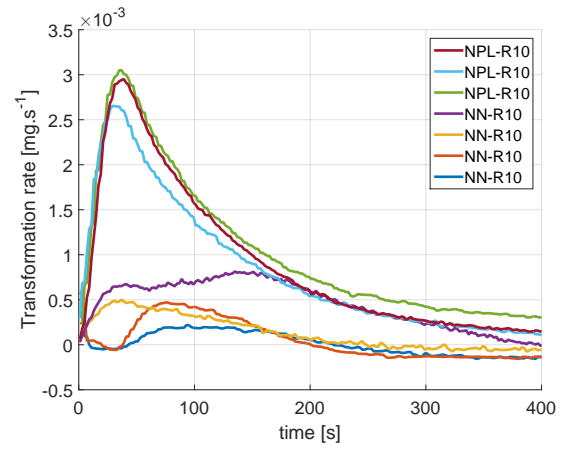

(b) Transformation rate

Figure 10: Thermogravimetric measurements for samples reduced for $10 \mathrm{~min}$

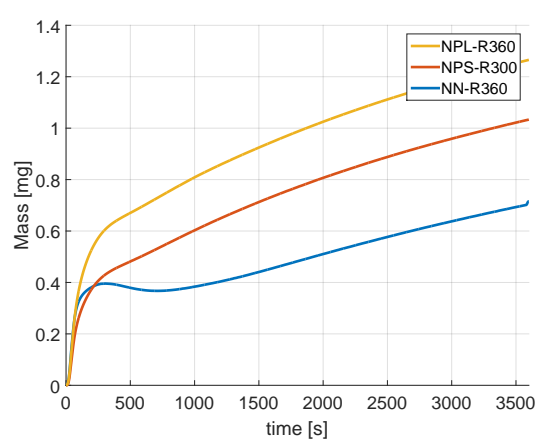

(a) Mass

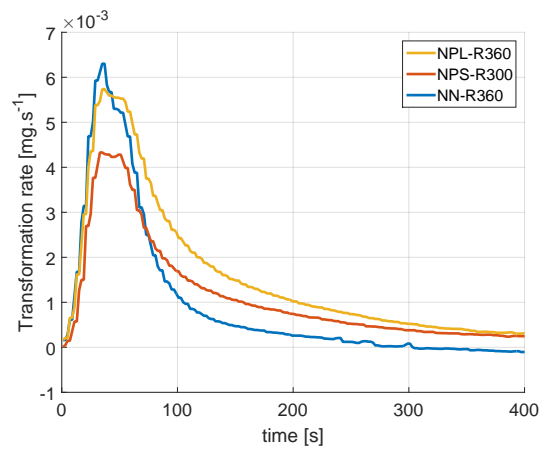

(b) Transformation rate

Figure 11: Thermogravimetric measurements for samples reduced for 5 to $6 h$. Influence of the nanostructuration duration

- Pure iron acts as a catalyst for ammonia dissociation. Without iron oxides, there only remains pure iron which enhances $\mathrm{NH}_{3}$ dissociation and improves nitriding kinetics. As mentioned by Arabczyk [28], the activation energy to dissociate ammonia is low with pure iron.

Figure 10 presents the thermogravimetric analysis curves for NN samples and NPL samples which all were reduced for $10 \mathrm{~min}$. One can see that only nanostructured samples present a peak during the first few minutes of nitriding. It leads to a higher mass after nitriding for this kind of samples. As shown on figure $7 \mathrm{~b}$, for reduction durations higher than $3 \mathrm{~h} 30 \mathrm{~min}$, the height of the peak 
does not change significantly. Samples which were reduced between 5 and $6 h$ are then comparable in regards to the influence of nanostructuration. Figure 11 presents the thermogravimetric curves for an NN sample, an NPS sample and an NPL sample which were reduced for 5 to $6 h$. It shows that all samples present a peak in their respective transformation rate curve during the first few minutes of nitriding. The peaks maxima are quite close except for the sample reduced $5 h$ and the peaks width increases with the nanostructuration duration. One might conclude that the diffusion of nitrogen is accelerated during a longer period of time. It also leads to higher mass for samples nanostructured for a long time.

These observations tend to show that reduction and NanoPeening ${ }^{\circledR}$ act in a similar way. Both treatments lead to an acceleration of nitrogen diffusion during the first few minutes. The main difference appears to be a higher transformation rate peak width in the case of NanoPeening ${ }^{\circledR}$. This might be explained by the following mechanisms :

- The reaction surface area is increased by the roughness created from the mechanical treatment.

- The NanoPeening ${ }^{\circledR}$ treatment leads to an increase in the grain boundary density which are fast diffusion channels $[12,4]$ on a few micrometers. It results in an acceleration of the nitrogen penetration and into a peak on the transformation rate curves. But contrary to the reduction effects which take place over the extreme surface (a few nanometers), the nanostructuration affects a few micrometers $[23,7]$, which are much larger. It can result in a wider peak for nanostructured samples than for the not treated ones.

The results above point out that both reduction and NanoPeening ${ }^{\circledR}$ treatments increases the diffusion kinetics of nitrogen. This is illustrated in Figure 12, which presents the mean transformation rate as a function of reduction duration. One may note that whatever the reduction duration, samples that have been mechanically treated, present higher mass rate. The peening treatment 


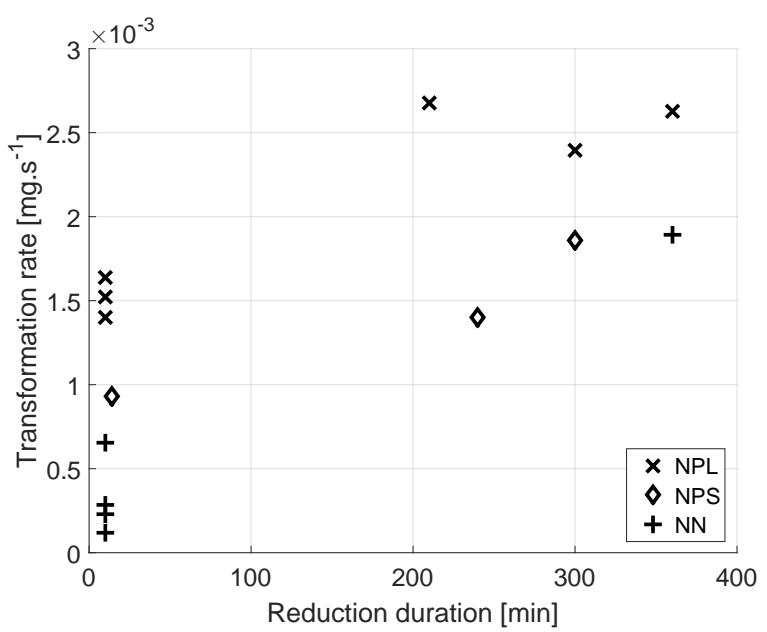

Figure 12: Mean transformation rate during the 200 first seconds of nitriding as a function of reduction duration for the three types of nanostructuration treatments

duration also plays a role on the diffusion kinetics as NPL samples are those presenting the highest mass rate.

The maximum value of the peak intensity (for all samples) is around $6.5 \times$ $10^{-3} \mathrm{mg} \cdot \mathrm{s}^{-1}$. Considering the ammonia flow of $0.6 \mathrm{~L} / \mathrm{h}$ and its density of $0.2697 \mathrm{mg} \cdot \mathrm{cm}^{-3}$ at $500{ }^{\circ} \mathrm{C}[29]$, the input nitrogen mass flow is around $37 \times$ $10^{-3} \mathrm{mg} \cdot \mathrm{s}^{-1}$. It is only 5.7 times the maximum peak intensity, which indicates that this value cannot be exceeded without increasing the incoming ammonia flow. It results in a saturation of the maximum value of the peak.

The absence of a concentration plateau on samples previously submitted to NanoPeening ${ }^{\circledR}$ is not easily explained. Here are several reasons which would lead to such concentration profiles regarding the NanoPeening ${ }^{\circledR}$ treatment. For instance, it may be due to the surface morphology after NanoPeening ${ }^{\circledR}$ or to the fact that the nitrogen solubility depends on the work hardening [30, 31]. As a matter of fact, this plateau is a consequence of the nitrogen solubility in iron according to $[25,32,26]$. Figure 13 shows the theoretical concentration profile of nitrogen after iron nitriding at a given temperature. Bounds of the concentration plateaus correspond to each phase limit at this temperature. 


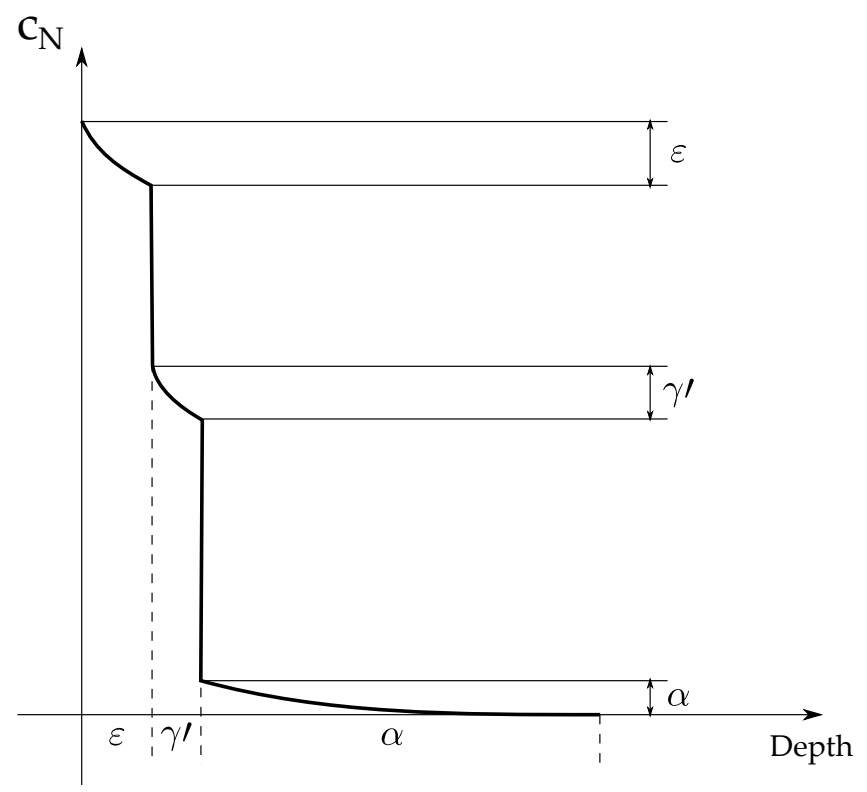

Figure 13: Theoretical concentration profile for $F e$ nitriding at a given temperature. The bounds of the different plateaus are given by the bounds of the different metallurgical phases

The solubility of nitrogen is given by the lowest of those limits. If this limit, and the limits of the other metallurgical domains change continuously with the depth (nanostructuration results in a grain size gradient along the depth of the material $[23,33,7])$ the concentration plateaus would not be visible anymore. This effect can be enhanced by an average effect due to the morphology of the nanostructured layer as shown on figure 14. At a given time, the GDOES device analyses a line which presents different deformation states. In addition to change continuously along the depth, the limits would change continuously along this analysis line, which would also result in a softer profile. Figure 15 shows an optical micrography of an NPL sample after nitriding. One can see a heterogeneous deformation of the material which leads to a variable thickness of the nitrided layer. From a practical point of view, it is a clear demonstration that in situ measurements like thermogravimetry have to come in addition to GDOES measurements to pursue this kind of investigation. Compared to metals of industrial use, where alloying elements can affect the oxidation, reduction 


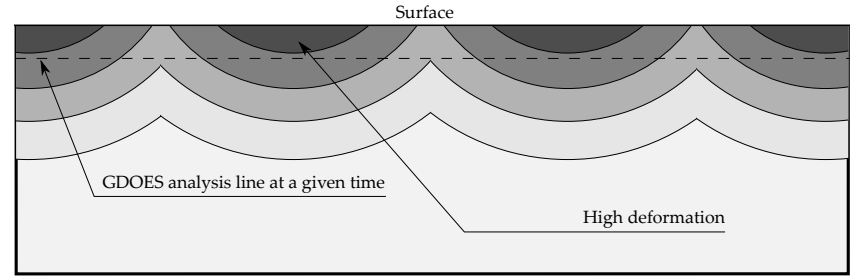

Figure 14: Average effect during GDOES analysis due to heterogeneous deformation

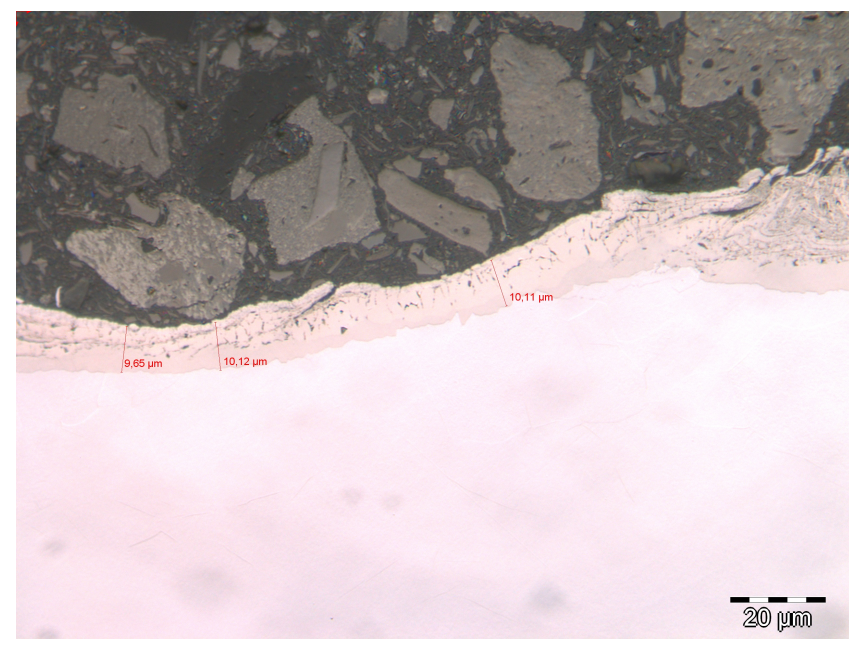

Figure 15: Optical micrography of a NPL sample after nitriding 
and nitriding phenomena, in pure iron no such contribution can occur. For this

study, it permits one to focus on the effect of reduction and NanoPeening ${ }^{\circledR}$ on nitriding. However, the low hardness of pure iron leads to the observed heterogeneous deformation. The NanoPeening ${ }^{\circledR}$ treatment is usually not applied to pure iron but to metals of industrial use, in particular steels. It is worth precising that steels, which are much harder than iron, would not exhibit such surface deformation when treated by NanoPeening ${ }^{\circledR}$.

- Formation of nitrides

- Thermodynamic interaction

\section{Conclusion}

In this paper, the combination of reduction and NanoPeening ${ }^{\circledR}$ treatments have been investigated on pure iron. This material has been chosen to avoid any effects of alloying elements on nitrogen diffusion and reaction. It permits one to draw the following conclusions, using thermogravimetric analysis and glow discharge optical spectrometry:

- Reduction mainly plays on the increase in reacting area and of the surface reactivity.

- NanoPeening ${ }^{\circledR}$ mainly acts on the increase in the effective diffusivity of the material in addition to the reacting area.

- The nitriding time required to reach a given mass can be significantly reduced by either reduction, nanostructuration or the combination of both.

- Beneficial effects of nanostructuration and reduction are cumulative.

To optimize the results given by such a combination, it is important to remember that NanoPeening ${ }^{\circledR}$ is derived from classical shot peening. So the treatment duration depends on the surface area, contrary to reduction treatment. A good compromise has to be found to obtain the required nitriding performances. For further studies on metals of industrial use, alloying 
elements may also play a role depending on the material composition and have to be taken into account. The same beneficial effects of both pre-treatments are expected on carbon steels, especially tool steels. Contrary to stainless steels, they would present iron oxides to be reduced and lead to a native metal surface. With nanocrystallization pre-treatment, nitrides and carbonitrides would be more dispersed in the matrix [13], leading to a faster diffusion of nitrogen.

\section{Acknowledgments}

The authors express their gratitude to Richard DROGO from École Des Mines de Saint-Étienne and to Bruno NICOLAS from LERMPS for their implication in this work. The GDOES equipment benefits from the financial support

of the FEDER, CG25, Pays de Montbéliard Agglomération and Région Franche Comté institutions through the PVDeFI project.

\section{References}

[1] G. Fallot, S. Jgou, L. Barrallier, Evolution of residual stresses during short time nitriding of 33crmov12-9 steel grade, Advanced Materials Research 996 (2014) 544-549, cited By 1. doi:10.4028/www.scientific.net/AMR.996.544.

[2] N.-R. Tao, M.-L. Sui, J. Lu, K. Lu, Surface nanocrystallization of iron induced by ultrasonic shot peening, Nanostructured Materials 11 (4) (1999) 433 - 440. doi:http://dx.doi.org/10.1016/S0965-9773(99)00324-4.

URL http://www.sciencedirect. com/science/article/pii/S0965977399003244

[3] N.-R. Tao, Z.-B. Wang, W.-P. Tong, M.-L. Sui, J. Lu, K. Lu, An investigation of surface nanocrystallization mechanism in fe induced by surface mechanical attrition treatment, Acta Mater. 50 (2002) 4603-4616.

[4] T. Prezeau, T. Muller, M. Baron, J. Samuel, E. Dransart, Surface treatment of a metal part, uS Patent App. 14/126,602 (Jun. 19 2014).

URL http://www.google.com/patents/US20140166160 
[5] E.-O. Hall, The deformation and ageing of mild steel: Iii discussion of results, Proceedings of the Physical Society. Section B 64 (9) (1951) 747.

[6] N.-J. Petch, The cleavage strength of polycrystals, J. Iron Steel Inst. 174 (1953) 25-28.

[7] D. Tumbajoy-Spinel, S. Descartes, J.-M. Bergheau, V. Lacaille, G. Guillonneau, J. Michler, G. Kermouche, Assessment of mechanical property gradients after impact-based surface treatment: application to pure $\alpha$-iron, Materials Science and Engineering: A 667 (2016) 189 - 198. doi:http://dx.doi.org/10.1016/j.msea.2016.04.059.

URL http://www.sciencedirect.com/science/article/pii/S0921509316304464

[8] J. Gu, D. Bei, J. Pan, J. Lu, K. Lu, Improved nitrogen transport in surface nanocrystallized low-carbon steels during gaseous nitridation, Mater. Lett. 340 (2002) 340-343.

[9] D. Moszyński, I. Moszyńska, W. Arabczyk, Iron nitriding and reduction of iron nitrides in nanocrystalline fen system, Materials Letters 78 (2012) 32 - 34, 30th Anniversary Special Issue. doi:http://dx.doi.org/10.1016/j.matlet.2012.03.047.

URL http://www.sciencedirect.com/science/article/pii/S0167577X12003990

[10] D. Moszyński, K. Kielbasa, W. Arabczyk, Influence of crystallites' size on iron nitriding and reduction of iron nitrides in nanocrystalline fen system, Materials Chemistry and Physics 141 (23) (2013) 674 - 679. doi:http://dx.doi.org/10.1016/j.matchemphys.2013.05.055.

URL http://www.sciencedirect.com/science/article/pii/S0254058413004379

[11] Y. Lin, J. Lu, L. Wang, T. Xu, Q. Xue, Surface nanocrystallization by surface mechanical attrition treatment and its effect on structure and properties of plasma nitrided aisi 321 stainless steel, Acta Mater. 54 (2006) $5599-5605$. 
[12] W.-P. Tong, Z. Han, L.-M. Wang, J. Lu, K. Lu, Low-temperature nitriding of $38 \mathrm{crmoal}$ steel with a nanostructured surface layer induced by surface mechanical attrition treatment, Surface \& Coating Technology 202 (2008) $4957-4963$.

[13] T. Prezeau, T. Muller, E. Dransart, Y. Giraud, Amélioration par un prétraitement mécanique de "nanopeening" des performances des traitements thermochimiques : Cas de la nitruration et de la carbonitruration basse pression., Traitements et Matériaux 412 (2011) 37-43.

[14] M. A. Terres, N. Laalai, H. Sidhom, Effect of nitriding and shot-peening on the fatigue behavior of $42 \mathrm{crmo} 4$ steel: Experimental analysis and predictive approach, Materials \& Design 35 (2012) 741-748.

[15] S.-M. Hassani-Gangaraj, A. Moridi, M. Guagliano, A. Ghidini, M. Boniardi, The effect of nitriding, severe shot peening and their combination on the fatigue behavior and micro-structure of a low-alloy steel, International Journal of Fatigue 62 (0) (2014) 67 - 76, 9th Fatigue Damage of Structural Materials Conference. doi:http://dx.doi.org/10.1016/j.ijfatigue.2013.04.017.

URL http://www.sciencedirect.com/science/article/pii/S0142112313001230

[16] S.-M. Hassani-Gangaraj, A. Moridi, M. Guagliano, A. Ghidini, Nitriding duration reduction without sacrificing mechanical characteristics and fatigue behavior: The beneficial effect of surface nano-crystallization by prior severe shot peening, Materials \& Design 55 (0) (2014) 492 - 498. doi:http://dx.doi.org/10.1016/j.matdes.2013.10.015.

URL http://www.sciencedirect.com/science/article/pii/S0261306913009424

[17] A. P. Manfridini, C. Godoy, J. A.-B. Wilson, M. V. Auad, Surface hardening of if steel by plasma nitriding: Effect of a shot peening pre-treatment, Surface and Coatings Technology 260 (2014) 168-178.

[18] M. Chemkhi, D. Retraint, A. Roos, C. Garnier, L. Waltz, C. Demangel, G. Proust, The effect of surface mechanical attrition treatment on low 
temperature plasma nitriding of an austenitic stainless steel, Surface and Coatings Technology 221 (2013) 191-195.

[19] J. R. Davis, Surface hardening of steels: understanding the basics, ASM international, 2002.

[20] D. Pye, Practical nitriding and ferritic nitrocarburizing, ASM international, 2003.

[21] E. D. L. Heras, G. Ybarra, D. Lamas, A. Cabo, E. L. Dalibon, S. P. Brhl, Plasma nitriding of $316 \mathrm{l}$ stainless steel in two different n2-h2 atmospheres influence on microstructure and corrosion resistance, Surface and Coatings Technology (2017) -doi:http://dx.doi.org/10.1016/j.surfcoat.2017.01.037.

URL http://www.sciencedirect.com/science/article/pii/S0257897217300361

[22] T. Jones, Oxidation pretreatment of steels for nitriding (September 2014). URL http://www . industrialheating.com/articles/91660-oxidation-pretreatment-of-steels-fo

[23] V. Lacaille, G. Kermouche, D.-Y. Tumbajoy-Spinel, E. Feulvarch, C. Morel, J.-M. Bergheau, Modeling nitriding enhancement resulting from the nanopeening treatment of a pure iron, IOP Conference Series: Materials Science and Engineering 63 (1) (2014) 012124.

[24] D. Wagner, Etude expérimentale et modélisation de la réduction du minerai de fer par l'hydrogène, Ph.D. thesis, Institut National Polytechnique de Lorraine-INPL (2008).

[25] M.-A.-J. Somers, 12.13 - development of compound layer and diffusion zone during nitriding and nitrocarburizing of iron and steels, in: S. H. F. B. J. V. T. Yilbas (Ed.), Comprehensive Materials Processing, Elsevier, Oxford, 2014, pp. 413 - 437. doi:http://dx.doi.org/10.1016/B978-0-08096532-1.01215-2.

URL http://wWw.sciencedirect.com/science/article/pii/B9780080965321012152

[26] L. Torchane, P. Bilger, J. Dulcy, M. Gantois, Control of iron nitride layers growth kinetics in the binary fe-n system, Metallurgical and Materials 
Transactions A 27 (7) (1996) 1823-1835. doi:10.1007/BF02651932.

URL http://dx.doi.org/10.1007/BF02651932

[27] F. Bonnet, Etude des mecanismes d'action du soufre sur le cokage catalytique du fer, Ph.D. thesis (2001).

[28] W. Arabczyk, J. Zamlynny, Study of the ammonia decomposition over iron catalysts, Catalysis Letters 60 (3) (1999) 167-171. doi:10.1023/A:1019007024041.

URL http://dx.doi.org/10.1023/A:1019007024041

[29] L. Haar, J. S. Gallagher, Thermodynamic properties of ammonia, Journal of Physical and Chemical Reference Data 7 (3) (1978) 635-792.

[30] H. A. Wried, L. S. Darken, Lattice defects and the solution of nitrogen in a deformed ferritic steel : Part i - experimental data and thermodynamic analysis, Transactions of the metallurgical society of AIME 233 (1965) 111122.

[31] H. A. Wried, L. S. Darken, Lattice defects and the solution of nitrogen in a deformed ferritic steel : Part ii - identification of defect ssite and influence of composition, Transactions of the metallurgical society of AIME 233 (1965) $122-130$.

[32] M.-A.-J. Somers, E.-J. Mittemeijer, Layer-growth kinetics on gaseous nitriding of pure iron: Evaluation of diffusion coefficients for nitrogen in iron nitrides, Metallurgical and Materials Transactions A 26 (1) (1995) 57-74. doi:10.1007/BF02669794.

URL http://dx.doi.org/10.1007/BF02669794

[33] V. Lacaille, G. Kermouche, D.-Y. Tumbajoy-Spinel, E. Feulvarch, C. Morel, J.-M. Bergheau, Modeling the nitrogen diffusion enhancement resulting from a nanopeening treatment on a pure iron influence of the grain morphology, Defect and Diffusion Forum 363 (2015) 178-185. 